\title{
Factors Influencing The Fluctuations of Nursing Staff
}

\section{E. Zacharova (Eva Zacharova)' , V. Kozon (Vlastimil Kozon)²}

${ }^{1}$ Department of Nursing, Dr. P. Blaho Intitute, J. Neumann Institute, Pribram, Czech Republic

${ }^{2}$ Allgemeines Krankenhaus, Vienna, Austria

\section{E-mail address:}

eva.zacharova@seznam.cz

\section{Reprint address:}

Eva Zacharova

J. Neumann Institute

Pribram

Czech Republic

Source: Clinical Social Work and Health Intervention Pages: $110-118$

Volume: 10

Issue: 2

Cited references: 26

\section{Reviewers:}

Jozef Matulnik

St. Elisabeth University of Health and Social Work, Bratislava, Slovakia

Harald Stefan

Vienna General Hospital, Vienna, Austria

\section{Key words:}

Nursing Staff. Fluctuation Factors. Intensive Care Nurses. General Ward Nurses.

\section{Publisher:}

International Society of Applied Preventive Medicine i-gap

CSWHI 2019; 10(2): 110 - 118; DOI 10.22359/cswhi_10_2_14 ( C) 2019 Clinical Social Work and Health Intervention

\section{Abstract:}

This article focuses on the problems connected with fluctuation of nursing staff. Today, the fluctuation of health care staff is a widespread phenomenon. This was further accentuated after the Czech Republic joined the EU as nursing staff started to make greater use of the free movement of people in the labor market. They departed to other countries as well as to more attractive workplaces which were less demanding on their personal, family and work life. It is for this reason that attention is paid to this problem. The main objective was to find out which 
selected factors influence the fluctuation of nursing staff and which serious factors influence the fluctuation. The chosen survey respondents were nurses working in intensive care units and general wards.

\section{Introduction}

Much has been written about the difficulties of the nursing profession. This issue is often discussed amongst health care professionals as well as the general public. It is important to realize that the nursing profession is demanding not only in terms of knowledge and practical skills but also in terms of the overall burden that often leads to fluctuation, which is a frequent phenomenon of this profession today. In recent years, health care facilities have not only faced fluctuation but also a considerable shortage of nursing staff. The International Labor Organi-zation and the World Health Organization labels the nursing profession as one of the professions most at risk of fluctuations.

Many authors have written about the expectations of the performance of the nursing profession and the descriptions of the personality requirements. Whether it is a description of character traits (17); dispositions towards work (15); or demands on the personality traits of the nurse and social prestige of the nursing profession (20). However, the views expressed on the personality of a professional nurse can be largely perceived as the theoretical desire of the authors to describe the ideal nurse and health care professional. The current understanding of personality prerequisites for the work of the nursing staff is based on a much more concise description of their characteristics, such as those reported by Goldmann, Cicha (9). In particular, these are traits of character on which good nursing care should generally be based.

Difficulties faced in the profession; great responsibilities in everyday clinical practice; physical or mental burden often affect the personal and professional life of the nursing staff. If staff are not given enough attention then their work tempo may not last long. Because of work overload, job dissatisfaction then occurs and subsequently fluctuation occurs.

Today, the fluctuation of nurses is a serious problem faced by most organizations around the world (21). According to Tourani et al. (2016) a fluctuation process is where an employee voluntarily leaves a job or organization. This is not a one-off event but it is the result of the alienation process which can take days, weeks, even years before the employee decides to leave.

The website Personalista.com (2017) indicates that fluctuations in health care in the Czech Republic ranks in third place, right after the manufacturing and media sector. The lack of nursing staff is a global problem and the Czech Republic is no exception. Low staff levels in the departments have an impact on the fatigue of nurses which thereby increases their intentions to leave (16). Gladkij (2003) states that the actual number of health professionals is growing but there is still a shortage of them on the labor market (8). This view is confirmed by data held in the Health Yearbook of the Czech Republic (22). The fluctuation of nursing staff is influenced by interconnected factors such as workload; working time; stress; burnout; quality of team leadership; interpersonal relationships in the workplace; lack of communication and management of employees; social considerations; career growth; further education; wage conditions (13). Currie and 
Carr Hill (2012) state that there is no particular reason for the fluctuation of the nurses but that it does change over time. Addressing the reasons for the fluctuation of nurses should be flexible and focus on the specific causes of this (6). The departure of key people can have a negative impact on the functioning of the organization (2). Health care facilities should therefore concentrate primarily on creating a positive working environment that will be a prerequisite for reducing the staff turnover of health care professionals (23).

\section{Objectives \& goals of the empirical research}

Determine which selected factors affect the fluctuation of nurses who work in intensive care units and standard wards.

\section{Sub-objectives \& goals:}

1. Determine what reasons the nurses have for considering leaving their existing workplace.

2. Determine the degree of perception of the mental demands of their work.

3. Determine whether interpersonal relationships in the workplace affect nursing satisfaction.

4. Determine to what extent wages affect nursing satisfaction.

\section{Survey respondents \& survey methods}

The group of survey respondents comprised a total of 192 nurses. There were 100 survey respondents (52\%) from the general ward and 92 survey respondents (48\%) from the intensive care unit. The largest group consisted of survey respondents aged 41 to 50 years old (35\%). Given the sensitivity of the topic, hospitals were divided into state and non-state types. The survey respondents had different lengths of work experience and different levels of education. The survey itself was preceded by a pilot study conducted at the Urgent Income Department (URGENT) of the University Hospital in Olomouc, Czech Republic. The quantitative scientific method was chosen for purposes of the research. Data collection was carried out using an electronic questionnaire which was created on the internet website www.my.survio.com. Anonymous data was processed. Microsoft Office Excel 2010 was the software program used to analyze the data. Collection of the research data took place between September 2017 and March 2018.

\section{Results and discussion}

The results obtained were compared with published research and the opinions of experts who have devoted a significant amount of time studying this topic. We have formulated the research objectives into four questions.

Research Question 1: Is there a higher rate of fluctuation for nurses who work in intensive care units than for nurses who work in general wards?

This question was to determine what percentage of the nurses who work in intensive care at the ICU, Anesthesiology \& Resuscitation, or Emergency Departments for both state as well as non-state health facilities in the Czech Republic are considering leaving their existing workplace. Results show positive findings where approximately $70 \%$ of survey respondents from both workplaces are not considering leaving work or only rarely. However, it is necessary to emphasize that these results apply only to the sample of survey respondents examined and cannot be applied to the whole population of nurses in Czech Republic. 36\% of survey respondents working in general wards would change their jobs for working reasons as 
would $41 \%$ of survey respondents working in intensive care departments. The working reasons included professional advancement; shiftwork; organizational changes in the workplace; interpersonal relationships; negative workplace atmosphere. With regards to survey respondents considering leaving the health sector, $62 \%$ of survey respondents working in the general ward would consider staying whilst $38 \%$ would leave the health care profession. While $82 \%$ of the intensive care survey respondents would consider staying, $18 \%$ would leave the health care profession. Gurkova et al. (2012) in an international cross-sectional study approached 1,055 nurses from the Slovak Republic and Czech Republic who worked in hospital inpatient facilities.

Research has explored the relationship between nurses' feelings and their considerations of leaving their profession. The research showed that the reason for the fluctuation of the nurses is job dissatisfaction and the subjective discomfort of the nurses. In Slovakia the reasons for the fluctuations of nurses in both examined phenomena included family relationships, personal life and health. Most of the nurses from Czech Republic cited overall job dissatisfaction as the cause for possible departure from their profession.

Reasons for leaving the workplace were largely associated with leaving the nursing practice completely or with the intention of leaving to go and work abroad. The results of the study show that labor uncertainty in the nursing profession has increased in the Czech Republic as well as the Slovak Republic which can thereby increase the risk of a shortage of nursing staff (10). In 2010, an international study entitled The European Nurses - Early Exit Study of European Nurses was conducted in Germany. This study was conducted in 71 departments from 16 hospitals. 2,119 nurses participated in the study. It was found that nurses from former post-communist countries (Poland, Slovak Republic) reported job dissatisfaction as the main reason for leaving their job, stating family reasons and poor working conditions (18).

Harokova and Gurkova (2015) investigated the available studies relating to job satisfaction in regard to the fluctuation of nurses. Their conclusion is to appeal to managers of health care facilities to develop strategies that will improve nurses' job satisfaction; strengthen interpersonal relationships; increase staff levels. Work relations; rewards; leadership style; leadership support; work environment; mental and physical stress are the most influential intentions to remain in existing employment (12).

Research Question 2: Is there a higher level of perception of mental demands in the nurses who work in intensive care units than the nurses in the general wards?

The mental demands of the nursing profession were verified. They may experience signs of burnout when they are exposed to severe mental stress for a long time (11). Many studies from around the world show that the nursing profession is a very mentally demanding profession. The results of the research confirmed that $93 \%$ of nurses perceive their work as being really mentally demanding. If we compare our chosen departments, it was proved that the majority of survey respondents perceive their work as mentally demanding. $94 \%$ of survey respondents working in the general ward perceived it as so with $92 \%$ of survey respondents in intensive care. From these results it is clear that the nurses who work in the general ward perceive the mental demands of the work slightly more than the nurses in intensive care. 
Survey respondents from both types of workplaces chosen by us state they are most stressed during shifts due to inadequate staff levels $(36 \%)$. The second most common response in the general ward was the amount of administrative work (26\%) and the second most common response in intensive care department was the number of work conflicts (26\%). Alarming, was the answer to the question about whether survey respondents often feel exhausted at work. $78 \%$ of survey respondents from general wards feel exhausted with $69 \%$ from intensive care departments feeling exhausted. Dawson et al. (2014) stated that the lack of qualified personnel in the treatment unit contributes to increasing the fatigue and nursed being overworked. These factors can lead to low levels of care and risks of undesirable events associated with patient care. Furthermore, research suggests that stress and burnout in nursing staff has led nursing staff to find another job (7). According to Branham (2009), long-term exposure to difficult situations (such as care for the dying, where quick decision-making is needed and where every second may decide a persons' life) leads to greater mental demands and towards gradual burnout of nurses.

The most at risk are nurses who work, for example, in Anesthesiology \& Resuscitation, ICU and Oncology Departments (5). Merlani et al. (2011) conducted an international multicentric study of burnout rates in ICU nurses working in Switzerland. 2,415 nurses participated in the study. The results showed that $28 \%$ of nurses have a high burnout rate. Most often this is due to age, excessive interest in work and no support from the family. In particular, nurses under 40 years of age show a high degree of burnout (14).

Research Question 3: Are nurses who have interpersonal workplace relationships more satisfied in the standard departments than nurses in the intensive care departments?

For this task, we investigated how interpersonal relationships in the workplace affect satisfaction. Working relationships are among the most important aspects of a quality workplace atmosphere. Communication, teamwork, and collaboration among the members of the health care team with focus on patient care are all important. As Vevoda states, teamwork is one of the main conditions for effective medical care but also nursing care (23). According to our findings, it was shown that $80 \%$ of nurses who work in the general ward are satisfied with workplace relationships while $58 \%$ of nurses who work in intensive care are satisfied with workplace relationships. Other research questions showed a positive conclusion, namely that workplace relations between nurses, doctors and superiors are assessed as good in both departments. However, it is surprising that $65 \%$ of survey respondents from intensive care units are thinking about changing positions because of workplace relationships while survey respondents working in a general ward would not make a change because of workplace relationships.

The recommendation to strengthen interpersonal workplace relations to reduce the fluctuation tendency of nurses is the result of many studies. High importance is placed on work relationships as these influence the retention of nurses in the wards (12). Bartlova and Hajduchova (2010) discovered in a research carried out in hospitals in the Czech Republic that, where the relationship between the attending nurses and the physician is positive, the attending nurses have less of a tendency to fluctuate than the nurses who evaluate the relationships with doctors as being negative. A third of survey respondents surveyed stated that another cause for 
fluctuation was due to a poor workplace environment and disagreements within the nursing team (3). Bartlova and Chloubova (2009) agree with these research results, stating that relationships between nursing staff and physicians play an important role in maintaining a good workplace atmosphere. The level of staff dissatisfaction is reflected in these relationships and consequently affects the quality of care. Doctors still often regard nurses with disrespect and may perceive nurses as subordinates to execute their orders (4). According to our survey, a surprising finding was made in that $45 \%$ of survey respondents in intensive care units perceive the atmosphere in the workplace as being tense. Whilst only $22 \%$ of survey respondents from the general ward perceive their workplace atmosphere as being tense. The fact is that healthy interpersonal relationships and mutual respect are the foundation of quality care, as individual members are dependent on each other for care, interpersonal needs and interpersonal relationships are highly reflected throughout the working environment and significantly affect the sick.

Research Question 4: Are nurses who work in intensive care units more satisfied with their wages than those who work in general wards?

There is no significant difference in the satisfaction regarding financial remunerations for nurses who work in general wards and nurses who work in the Anesthesiology $\&$ Resuscitation and ICU Units. A surprising finding was that $67 \%$ of survey respondents from intensive care units are satisfied with their wage. $52 \%$ of survey respondents from the general ward are also satisfied. Interestingly, for $59 \%$ of survey respondents, wages are not the reason to consider changing their jobs. However, the vast majority of research stated low pay and under-valuation as possible causes of fluctuation. This is confirmed by Bartova and Hajduchova's research (2010) that stated that low pay, together with a great administrative burden, contributes towards the nursing staff leaving the profession (3).

Results of a national research study by Dawson et al. (2014) agree with previous results and that low appreciation of the work of the nursing staff seemed to be demotivating for them and also led to a fluctuation of the nursing staff. This research was conducted in three Australian states (7). Aiken et al. reached the same conclusions in a cross-sectional study conducted in 12 European countries. 33,659 nurses participated in the study. Research suggests that low wages and insufficient remuneration for work performed have led to fluctuations (1). In the quantitative study, Spurna-Dolezalova (2014) again concluded that the reason for the fluctuation of the nursing staff was mainly due to insufficient financial remuneration. 192 Czech nurses who performed bedside rounds participated in this study. These were nurses who worked in cities where there is more choice of health care facilities. During this study, 13\% of survey respondents considered leaving or were already serving their notice period. The main reason for fluctuation in Czech nursing staff that participated in the research was insufficient financial remuneration (19).

\section{Improvement recommendations}

There are several improvement recommendations based on the results of the research investigation that was carried out and from the study of professional literature. These recommendations can be beneficial not only for top managers of hospitals but also for middle management in the workplaces. 


\section{Recommendations for top manage- ment:}

- Contribute to job satisfaction and prevention of staff weakness by having a suitable organizational culture.

- Collaboration between individual line managers across the entire health care facility where the demands for care are high.

- Collaborating with work psychologists, introducing peer care and supervision in the health care facilities.

- Consider the introduction of stress management training to support the relationship between nurses and managers.

- Systematically evaluate fluctuation indicators within the management of individual workplaces.

\section{Recommendations for middle man- agement:}

- Ensure optimal sizes of the teams.

- Place emphasis on suitable staff qualifications to ensure an optimal ratio of qualified nurses.

- Reduce the nursing workload and provide enough numbers of nursing staff.

- Focus on the work atmosphere and work relationships that require special attention and provide feedback on the performance of their work tasks.

- Regularly ensure time-outs (rest breaks)

- Create more opportunities for communication through group discussions, operational meetings or regular meetings for that purpose.

- Provide appreciation, recognition and provide the same emotional support to all staff.

\section{Conclusion}

A serious shortage of professional nurses and the increasing fluctuation is alarming for all health care facilities. The nursing profession is a very demanding profession in terms of training, performance and responsibilities especially in recent years in connection with the rapid development of medicine and the development of nursing as a science. Nurses are difficult to replace and this is compounded by the current situation in the labor market. Nowadays, the situation in some workplaces, predominantly non-state institutions, is critical and there is a reduction in the number of beds as well as the closing down of individual departments. The difficulty of working in the health sector cannot be alleviated and continues to grow. Adequate numbers of support staff are needed to alleviate the workload as to not burden qualified nurses with menial work. Management must regularly evaluate the work of the nurses and fully appreciate them. This is the only way to create a positive working environment which in turn positively affects the workplace atmosphere and reduces fluctuation.

\section{References}

1. AIKEN L H, SLOANE D M, BRUYNEEL L, VAN DEN HEEDE K, SERMEUS W (2013) Nurses' reports of working conditions and hospital quality of care in 12 countries in Europe. International Journal of Nursing Studies, 50, 2, p. 143-153. doi: 10.1016/j.jnurstu. 2012.11.09.

2. ARMSTRONG M, TAYLOR M (2015) Human Resource Management. Prague: Grada, 2015. 928 pages. ISBN 978-80-247-5258-7.

3. BARTLOVA S, HAJDUCHOVA H (2010) Psychological and physical burden and the causes of the nurses fluctuation. Health care in the Czech Republic, 13, 3, p. 110-115. ISSN 1213-6050.

4. BARTLOVA S, CHLOUBOVA I (2009) Positions of nurse in multidisciplinary teams. Kontakt, 11, 1, p. 252-256. ISSN 1212-4117. 
5. BRANHAM L (2009) 7 hidden reasons why employees leave companien. Prague, Grada, 227 pages. ISBN 978-80-247-2903-9.

6. CURRIE E J, CARR HILL R A (2012) What are the reasons for high turnover in nursing? A discussion of presumed causal factors and remedies. International Journal of Nursing Studies, 49, 9, p. 1180-1189, doi: 10.1016/j.ijnurstu.2012.01.001. ISSN 00207489.

7. DAWSON A J, STASA H, ROCHE M A, HOMER C S E, DUFFIELD CH (2014). Nursing churn and turnover in Australian hospitals: nurses perceptions and suggestions for supportive strategies. BMC Nursing, 13, 11, doi: 10.1186/1472-695513-11. ISSN 14726955. 20 pages. online: https://bmcnurs.biomedcentral.com/articles/10.1186/1472-6955-13-11

8. GLADKIJ I (2003) Health care Management. Brno: Computer Press, 2003. 380 pages. ISBN 978-80-7226-996-9.

9. GOLDMANN R, CICHA M (2004) Ethics of health and social work. Olomouc: UP, 126 pages. ISBN 80-244-0907-0.

10. GURKOVA E, MACEJKOVA S (2012) Mental stress and depressive symptomatology in nurses. Nursing and Midwifery, 3, 1, p. 326-334. ISSN: 1804-2740. online: http://periodika.osu.cz/osetrovatelstviaporodniasistence/dok/2012-01/1_gurkova_ macejkova.pdf

11. HAMAIDEH S H, MRAYYAN M T, MUDALLAL R, FAOURI I G, KHASAWNEH N A (2008) Jordanian nurses' job stressors and social support. International Nursing Review, 55, 1, p. 40-47. doi: 10.1111/j.1466-7657.2007.00605.x.

12. HAROKOVA S, GURKOVA E (2012). Factors affecting satisfaction of Czech nurses with work. Kontakt, 14, 4, p. 401409. ISSN: 1212-4117. online: https://kont. zsf.jcu.cz/pdfs/knt/2012/04/01.pdf

13. HAYESAL J, O'BRIEN-PALLASA L, DUFFIELD CH, SHAMIAN J, BUCHAN J, HUGHES F, HEATHER K,
LASCHINGER S, NORTH N (2012) Nurse turnover: A literature review - An update. International Journal of Nursing Studies, 49, 7, p. 887-905. ISSN: 00207489. doi: 10.1016/j.ijnurstu.2011.10.001. online: http:/www.sciencedirect.com/science/article/pii/S0020748911003798

14. MERLANI P, VERDON M, BUSINGER A, DOMENIGHETTI G, PARGGER H, RICOU B (2011) Burnout in ICU Caregivers: A Multicenter Study of Factors Associated to Centers. American Journal of Respiratory and Critical Care Medicine, 184, 10, p. 1140-1146. doi: 10.1164/ rccm.201101-00680C. online: https:// www.atsjournals.org/doi/full/10.1164/rccm.201101-00680C

15. PLEVOVA I et al. (2012) Management in Nursing. Prague: Grada. 304 pages. ISBN 978-80-247-3871-0.

16. INTERNET WEBSITE PERSONALISTA.COM. online: http://www.personalista. com/Hamad Medical Corporation. ISSN 1214-7419. online: https://www.hamad.qa/ EN/Hospitalsandservices/Nursing/NMER/ Programs/CorePrograms/Pages/Preceptorship-Program.aspx.

17. ROZSYPALOVA M et al. (1978) Caring for the sick. Prague: Avicenum, 1978. 354 pages.

18. SIMON M, MÜLLER B H, HASSELHORN H M (2010) Leaving the organization or the profession - a multilevel analysis of nurses ' intentions. Journal of Advanced Nursing, 66,3, p. 616-626. doi: 10.1111/j.13652648.2009.05204.x. ISSN: 0309-2402.

19. SPURNA-DOLEZALOVA M (2014) Fluctuation of nurses in health care facilities. Florence, 10, 4, p. 28- 31. ISSN 1801-464X.

20. STANKOVA M (2001) Czech nursing. Brno: Institute for Further Education of Health Care Staff in Brno. 86 pages. ISBN 80-7013-329-5.

21. TOURANI S, KHOSRAVIZADEH O, OMRANI A, SOKHANVAR M, KAKEMAM E, NAJAFIB(2016) The relationship 
between organizational justice and turnover intention of hospital nurses in Iran. Materia Sociomedica, 28, 3, p. 205-209. ISSN 1512-7680, online: https://www.ncbi.nlm. nih.gov/pmc/articles/PMC4949048/.

22. UZIS, Institute of Health Information and Statistics of the Czech Republic (2016). online: http://www.uzis.cz/katalog/rocenky/ zdravotnicka-rocenka-ceske-republiky.

23. VEVODA J et al. (2013) Motivating nurses and working satisfaction in health care. Prague: Grada, 160 pages. ISBN 978-80247-4732-3.

24. ARPOVA A (2018) Prevention of socio-pathological phenomena in adolescents. Monograph 100\%. 1 vyd. St. Elizabeth University of Health and Social Work Bratislava. 172 pp. Publisher: Art AIR CENTER, Dolny Kubin. ISBN 978-80-8132-186-3.
25. SILHAR B, SUVADA J, MIKOLASOVA G, MAMOVA A, BELOVICOVA M, BARTOSOVIC I, KRCMERY V, HRINDOVA T, RIDOSKO J, HAJJ P A (2017) Rapid diagnostic tests correlates with microscopy but not $C$-reactive protein among HIV positive rural population with malaria in Central Uganda (Research note). In Clinical Social Work and Health Intervention. Vienna: GAP, 2017. No. 3. Vol. 8. 58 - 61 p. DOI 10.22359/cswhi_8 3 11. ISSN 2222-386X.

26. KOVAC R, POLONOVA J, PROCHAZKOVA K, MIKOLASOVA C, KRCMERY V, BERNADIC M, KISAC P, KALAVSKY E, MRAZOVA M, MATEICKA F, LISKOVA A, MAMOVA A, OLAH M, HERDICS C, IBRAHIM M (2018) Absence of TB and HIV in sheltered homeless population of Bratislava (Slovakia) In Lekarsky Obzor. Vol 67, No 6, pp 202-203. ISSN 04574214. 